Editorial

\title{
Service and Life Cycle Management of engineered assets/goods
}

\section{Introduction}

This article provides an introduction to the special issue dedicated to Service and Life Cycle Management of engineered assets/ goods. Managing engineered assets and goods requires integrative organizational practices to ensure low life cycle costs, high reliability and availability, at maximum safety levels. These integrative practices have always been at the forefront of the research of guest editor dr. Warse Klingenberg. Warse Klingenberg, who was an associate professor of Industrial Engineering, passed away in December 2013. We dedicate the introduction to this special issue to him. We start off with a short in memoriam. Thereafter, we share the vision of dr. Klingenberg on this field which also formed the inspiration for this special issue.

Warse Klingenberg, who received his $\mathrm{PhD}$ in mechanical engineering, has been active in consulting and conducting research at major engineering and maintenance contractors. The questions driving his professional activities have always been structured around the process improvement of firms engineering, producing and servicing/maintaining engineered assets/goods. In doing so he always had an open eye for questions that were both theoretically and practically grounded. This was underlined by the fact that he received many Dutch research grants for projects driven by industrial reality, targeted towards improved theoretical understanding. Warse established a clear line of thought in terms of teaching as well. The Master course Asset management he developed with colleagues from the University of Groningen now serves as a basis for teaching young professionals the essentials of Service and Lifecycle Management of engineered goods/assets. Warse delighted his colleagues, and his PhD students in particular, with his pragmatic and practical view on researching and teaching asset management. We are very sad to see that his life ended too soon.

\section{Trends and topics in the Service and Life Cycle Management of engineered assets/goods}

Service and Life Cycle Management is a multidisciplinary and long-term management perspective on the management of capital assets. The field comprises the integral management of the design, engineering, construction, maintenance, production and decommissioning phases of an asset. It can be viewed as a managerial answer to the increasingly competitive and changing environment which change the requirements of engineered goods/assets. In memory of Warse, we introduce several topics in line with his vision and research that, in our opinion, have the potential to develop in the coming years as important areas of research in the field of Service and Life Cycle Management of engineered assets/goods and practice.

\subsection{Dynamic maintenance concepts}

A company can optimize the use and maintenance of its assets by continuously aligning operations and service strategies with the business strategy and environment. The application of dynamic maintenance concepts and processes is one of the research directions within the field of asset management which received considerable attention of Warse Klingenberg. Observations show that there is a clear need for a maintenance organization that is able to cope with internal and external changes.

Following knowledge gained in Lean manufacturing, Warse believed in the development of organizational process capabilities and conditions that need to be fulfilled to make fundamental maintenance process improvements possible. Veldman and Klingenberg (2009) demonstrated that the Capability Maturity Model Integrated (CMMI), a best practice reference framework widely used in the software industry can be applied to companies active in asset management on an engineer-to-order basis.

One of the best maintenance strategies to cope with unpredictable use and subsequent asset load changes is Condition Based Maintenance (CBM). CBM has been receiving increasing attention by researchers and practitioners. CBM is not only economically interesting but its implementation has also received a technology push by the increasing availability of sensor and control technologies. It is not always easy to assess whether CBM is economically worthwhile and technically feasible as there is a need to integrate technical, economical and organizational knowledge. Research by Koochaki, Bokhorst, Wortmann, and Klingenberg (2012, 2013) shows that CBM is not always the best strategy; especially when CBM is used as the dominant maintenance strategy, unpredictability shifts from the operation itself to maintenance. This unpredictability complicates the planning and efficient clustering of maintenance activities.

One of the main decisions influencing the successful implementation of CBM is choosing an effective CBM analysis strategy. Veldman, Wortmann, and Klingenberg (2011) have therefore proposed a typology for CBM that can be used to identify the analysis strategy based on the analysis tasks, type of available data (i.e. process data or failure data), and the technical and organizational requirements. A particular strength of the typology is the identification of the knowledge needed to successfully implement CBM.

Another interesting area includes the design of proper maintenance strategies to achieve strategic alignment of the maintenance 
function. One way to do this is by dynamically optimizing the frequency of planned maintenance activities with respect to changing asset loads and asset failure predictions. Braaksma, Klingenberg, and Veldman (2013) show that changes to maintenance plans are often made reactively without reviewing the rationale behind the maintenance concept itself. One of the causes is that the currently applied maintenance processes and the frameworks used for maintenance concept development such as Reliability Centred Maintenance (RCM) and Failure Mode and Effects Analysis (FMEA), are designed and implemented as a one-time exercise for the initial maintenance planning of an asset. This hinders an organization to reinterpret and re-use existing analyses and to learn from past maintenance decision making.

Consequently, we indicate a need to research how the current maintenance concept development processes and tools can be made suitable for re-use. The Maintenance Feedback Analysis (MFA), proposed by Braaksma (2012), is a framework developed as an extension to RCM/FMEA analysis. It identifies and evaluates future maintenance improvement opportunities and helps to organize the subsequent data collection and analysis needed for future improvement at the moment the RCM/FMEA analysis is conducted. Another approach facilitating repetitive maintenance activities is to quantify the underlying rationale of maintenance concepts, such as proposed by Braaksma, Meesters, Klingenberg, and Hicks (2012).

\subsection{Asset information management}

The way information is described, managed and exchanged is the basis for optimizing asset management concepts. Despite the enormous amounts of available data, various serious information management problems might be noticed in organizations. These problems vary from information quality problems, data uncertainty and difficulties with the exchange of data, to the ability to interpret this information without contextual knowledge (Braaksma, 2012). Dealing with context is difficult, as available models and tools reported in the literature often have a high data quality need typically unavailable in practice. Recent studies have focused on the design of robust models and tools capable of dealing with data with limited quality (e.g., De Jonge, 2014).

Another approach aimed at solving one of the deeper causes of data quality problems is to make use of (asset information) standards for the management and exchange of asset information (Braaksma, Klingenberg, \& Van Exel, 2011). Asset information standards ought to be used for (non-changing) data such as the hierarchical structure of a (part of a) capital good and the uniform description of failure modes, failure occurrences and failure causes. The adoption of these standards is often limited in practice because of various standards-, organization- and environment-related reasons, which are reviewed by Braaksma et al. (2011) in the process industry. The same research showed that simple and smaller standards designed for a single purpose tend to be more successful than larger standards designed for more diverse needs. Future research could therefore focus on the design and implementation of smaller standards for a limited purpose while still being compliant to larger 'mother standards'.

\subsection{Life cycle planning}

The ageing of our assets, often built after the Second World War, and the demand for more sustainable production has resulted in a desire to make the most out of the (potential) value of assets by optimizing operations, design and maintenance. Deeper insight into assets along the entire lifetime is therefore essential. Currently many methods such as RCM are often only focused on the short and medium term and are typically only carried out shortly after the commissioning of the asset. Furthermore they only take a narrow perspective into account, for example only a technical or financial perspective. In addition, many methods seem to be highly dependent on quantitative data. There is, therefore, a need for the development of multidisciplinary methods for asset lifecycle planning. Instead of primarily aiming at determining remaining lifetime, it can be argued that lifecycle planning should focus on the efficient and effective identification and mitigation of asset lifetime impacts (e.g., Ruitenburg, Braaksma, \& Dongen van, 2014).

\subsection{Contracting/performance based logistics}

Warse Klingenberg has always argued that improving asset performance requires cooperation between asset owners and service providers, based on trust and mutual dependencies. However, closer cooperation of companies also brings in new (legal) risks which need to be mitigated. This makes it more important to better understand the interaction between maintenance planning and execution, and the parameters included in (performance-based) maintenance contracts. Together with his co-workers, Warse has set the stage (e.g., Veldman, Klingenberg, Gaalman, \& Teunter, 2014) to investigate the complex interaction between advanced maintenance concepts and contracting strategies.

\section{Introduction to the special issue}

This special issue aims to contribute to the development of multi-disciplinary research on the supply of engineering goods and technology. Engineered goods and assets are by nature customized and are often innovative, complex and capital intensive with long life cycles. A wide range of services is typically involved throughout the life cycle; from offering turnkey design \& engineering services through to production/construction, maintenance, through-life support and end-of-life management. This requires an integrated approach to project management, design, engineering, production, supply chain management and maintenance. In many cases these changes have driven industrial consolidation and the forming of consortia as large-scale organizations have been best placed to meet the new requirements. There appears to be a gap between the importance of such integrative approaches in practice and the level of attention paid to them in the academic literature. Three papers have been accepted to appear in this special issue. We introduce each of the three papers in short.

3.1. Gustavsson, E., Patriksson, M., Strömberg, A.-B., Wojciechowski, A., Önnheim, M., Preventive maintenance scheduling of multicomponent systems with interval costs

Gustavsson et al. focus on the area of dynamic maintenance by studying a preventive maintenance concept with corrective maintenance activities. The authors study the scheduling of component replacement over time with the objective to minimize costs and meet replacement interval constraints. Theoretical insights with regard to problem characteristics are shown. Three studies on the practical applicability are introduced, namely rail grinding and component replacement in aircraft engines and wind mills in wind farms.

\subsection{Dixit, V., Srivastava, R.K., Chaudhuri, A., Procurement scheduling for complex projects with fuzzy activity durations and lead times}

Dixit et al. study material procurement decision problems for complex problems with long manufacturing times such as ships 
and aircrafts under data uncertainty. Information on lead times, availability dates and activity duration typically encaptures a high amount of uncertainty. The authors introduce a solution method with the aim to minimize holding and shortage costs. A study is performed for a real ship building project. The model together with sensitivity analyses help identifying sensitive stages of the project.

3.3. Hinckeldeyn, J., Dekkers, R., Altfeld, N., Kreutzfeldt, J., Expanding Bottleneck Management from Manufacturing to Product Design and Engineering Processes

Hinckeldeyn et al. focus on the design and engineering phase of products. More specifically, the authors extend manufacturing bottleneck management research to these two phases. System theory modelling is used to develop a new concept consisting of four bottleneck management measures. Event-discrete simulation has been used as a means to test propositions and to validate the methods designed with empirical data. The studies confirm practical applicability of the concepts also in the design and engineering phase of products.

\section{References}

Braaksma, A. J. J., Klingenberg, W., \& Van Exel, P. W. H. M. (2011). A review of the use of asset information standards for collaboration in the process industry Computers in Industry, 62(3), 337-350.

Braaksma, A.J.J. (2012). Design of a Maintenance Feedback Analysis (MFA) method for continuous FMEA-based maintenance, in: Asset information for FMEA-based maintenance, PhD dissertation, Faculty of Economics and Business, SOM, University of Groningen.

Braaksma, A. J. J., Meesters, A. J., Klingenberg, W., \& Hicks, C. (2012). A quantitative method for failure mode and effects analysis. International Journal of Production Research, 50(23), 6904-6917.

Braaksma, A. J. J., Klingenberg, W., \& Veldman, J. (2013). Failure mode and effects analysis for maintenance planning: A multiple case study in the process industry. International Journal of Production Research, 51(4), 1055-1071.
De Jonge, B. (2014). Optimality criteria for age-based maintenance planning under uncertainty in the lifetime distribution. In: 8th IMA international conference on modelling in industrial maintenance and reliability, Oxford, United Kingdom.

Koochaki, J., Bokhorst, J. A. C., Wortmann, J. C., \& Klingenberg, W. (2012). Condition based maintenance in the context of opportunistic maintenance. International Journal of Production Research, 50(23), 6918-6929.

Koochaki, J., Bokhorst, J. A. C., Wortmann, J. C., \& Klingenberg, W. (2013). The influence of condition-based maintenance on maintenance scheduling and workforce planning. International Journal of Production Research, 51(8), 2339-2351.

Ruitenburg, R., Braaksma, A. J. J., Dongen van, L. A. M. (2014). A multidisciplinary approach for the identification of impacts on the useful remaining lifetime of assets. In: 3rd International conference on through-life engineering services, Cranfield University, United Kingdom.

Veldman, J., \& Klingenberg, W. (2009). Applicability of the capability maturity model for engineer-to-order firms. International Journal of Technology Management, 48(2), 219-239.

Veldman, J., Wortmann, J. C., \& Klingenberg, W. (2011). Typology of condition based maintenance. Journal of Ouality in Maintenance Engineering, 17(2), 183-202.

Veldman, J., Klingenberg, W., Gaalman, G. J. C., \& Teunter, R. H. (2014). Getting what you pay for-strategic process improvement compensation and profitability impact. Production and Operations Management, 23(8), 1387-1400.

A.J.J. (Jan) Braaksma Department of Design, Production and Management, Faculty of Engineering Technology, University of Twente, Enschede, The Netherlands

J. (Jasper) Veldman I.F.A. (Iris) Vis*

Department of Operations, Faculty of Economics and Business, University of Groningen, Groningen,

The Netherlands

* Corresponding author. E-mail address: i.f.a.vis@rug.nl (I.F.A. (Iris) Vis)

Available online $\mathrm{xxxx}$ 